Estudios Constitucionales, Año 17, No 1, 2019, pp. 15-52

ISSN 07180195

Centro de Estudios Constitucionales de Chile Universidad de Talca

"El nuevo autoritarismo latinoamericano: Un reto para la democracia y los derechos humanos (análisis del caso venezolano)"

Ronald Chacín Fuenmayor

\title{
EL NUEVO AUTORITARISMO LATINOAMERICANO: UN RETO PARA LA DEMOCRACIA Y LOS DERECHOS HUMANOS (ANÁLISIS DEL CASO VENEZOLANO)*
}

\author{
THE NEW LATIN AMERICAN AUTHORITARIANISM: \\ A CHALLENGE FOR DEMOCRACY AND HUMAN RIGHTS \\ (ANALYSIS OF THE VENEZUELAN CASE)
}

\author{
Ronald Chacín FuenMayoR ${ }^{*}$ \\ Universidad del Sinú Elías Bechara Zainúm \\ palante.rochafu15@gmail.com
}

RESUMEN: La democracia en varios paises latinoamericanos está en declive, concretamente en aquellos donde, a pesar de ser elegidos sus gobernantes democráticamente, limitan los derechos civiles y politicos de los ciudadanos y se establecen de manera ilimitada en el poder, mediante la reelección indefinida, como en el caso de Venezuela, proceso que está replicándose en Bolivia y Nicaragua. El trabajo se plantea desde un abordaje teórico político sobre esta problemática, centrándose particularmente en Venezuela, mediante tres aspectos: análisis teórico de los regímenes no democráticos; revisión de las doctrinas democráticas contemporáneas, que incluye la democracia constitucional, y finalmente, la descripción de los elementos autoritarios que caracterizan el caso de Venezuela. Se concluye que uno de los principales factores que explican el surgimiento del autoritarismo en Venezuela lo constituye la apropiación del Poder Judicial por parte del jefe de Estado, quien lo coloca a su servicio para autorizar institucionalmente sus arbitrariedades, las cuales lesionan la forma de gobierno democrático y los derechos fundamentales que la componen.

ABSTRACT: Democracy in several Latin American countries is in decline, specifically in those where, despite being democratically elected, rulers limit the civil and political rights of citizens and establish themselves unlimitedly in power, through indefinite re-election, as in the case of Venezuela, a process that is being replicated in Bolivia and Nicaragua. The work is proposed from a theoretical and political approach to this problem, focusing particularly on Venezuela, through three aspects: theoretical analysis of undemocratic regimes; revision of the contemporary democratic doctrines, which includes the constitutional democracy, and finally, the description of the authoritarian elements that characterize the Venezuela case. It is concluded that one of the main factors that explain the emergence of authori-

\footnotetext{
* Trabajo recibido el 21 de mayo de 2018 y aprobado el 17 de enero de 2019.

** Docente e investigador. Abogado Summa Cum Laude. Magíster en Derecho. Magíster en Ciencia Política. Doctor en Derecho (Títulos de la Universidad del Zulia Maracaibo-Venezuela, profesor emérito de esta casa de estudios). Actualmente docente e Investigador de la Universidad del Sinú Elías Bechara Zainum de Montería-Colombia.
} 
tarianism in Venezuela, is the appropriation of the Judiciary by the head of state, who places it at his service to institutionally authorize his arbitrariness, which injures the democratic form of government and the fundamental rights that it comprises.

PaLABRAS CLAVE: Autoritarismo, Latinoamérica, Democracia, Derechos Humanos.

KEY WORDS: Authoritarianism, Latin America, Democracy, Human Rights.

\section{INTRODUCCIÓN}

El autoritarismo y demás formas de gobierno o regímenes no democráticos constituye una temática que tiene vigencia en el mundo, aunque parecía que estaba superada en nuestro ámbito latinoamericano, que tenía democracias en líneas generales más o menos consolidadas.

No obstante, la crisis económica de los años 80 y 90, que permeó gran parte de los países latinoamericanos, contribuyó grandemente a su fragilidad, generando mucha inestabilidad que incluso llevó a alzamientos militares y cambios irregulares de los gobernantes de Ecuador, Argentina, Venezuela y Perú, entre otros.

Luego de un período de encauzamiento democrático, emergieron y se consolidaron regímenes que fueron coartando derechos civiles y políticos de una manera progresiva, tanto que hoy se pueden calificar como no democráticos o autoritarios. Es el fenómeno que afecta a varios países, destacando el caso de Venezuela, que entre otras situaciones arbitrarias ha establecido la reelección indefinida, que atenta de manera contundente contra la alternabilidad política y por ende contra la democracia; esta reelección fomenta gobiernos dictatoriales y totalitarios, ya que contribuye a la prolongación del mandatario de manera intemporal en el poder.

En este sentido, puede decirse que la reelección indefinida es una categoría que atenta contra la alternabilidad democrática y que además de Venezuela se ha replicado en Nicaragua y Bolivia, pudiendo intuirse que estamos ante el surgimiento de un nuevo autoritarismo en la región, por las consecuencias negativas que este tipo de reelección puede tener para la democracia ${ }^{1}$.

El caso de Venezuela constituye el interés de análisis en este trabajo; además, sobre él se dispone de más datos. Se trata de un caso típico por tratarse de líderes elegidos democráticamente, pero que gradualmente avanzan, comportándose de manera arbitraria en la restricción de los derechos civiles y políticos a sus ciu-

\footnotetext{
1 No obstante, en el presente trabajo no se ahondará ni en Bolivia ni en Nicaragua, cuestión que es razonable analizar para constatar si el autoritarismo es solo en Venezuela o en otros países de la región. Sin embargo, tal análisis sobrepasaría los objetivos y la extensión del presente trabajo.
} 
dadanos $^{2}$. Estas formas de gobierno se consideran también como "democracias delegativas" 3 , por cuanto el gobernante electo asume que luego de ser elegido democráticamente mediante sufragio universal, está habilitado para tomar medidas personalistas, con ribetes autoritarios, especialmente cuando consigue algún freno constitucional o legal para el despliegue de los objetivos de su gobierno, es decir, actúa como un "césar elegido"4.

Sobre la base de lo expuesto, el presente estudio tiene como fines avanzar en la construcción del recorrido teórico sobre las propuestas teórico democráticas y no democráticas de los regímenes políticos. $\mathrm{Al}$ mismo tiempo, se hará una breve descripción de los mismos; finalmente, realizará una síntesis que apunte a caracterizar el autoritarismo del régimen político venezolano.

El contenido comprenderá tres partes: 1) la descripción teórica de los gobiernos no democráticos; 2) un recorrido por las teorías democráticas contemporáneas y sus principales elementos, incluyendo la democracia constitucional, y 3) la descripción del régimen político venezolano, que comprende la síntesis de los efectos de este sobre la teoría política y los derechos constitucionales o fundamentales.

Se aclara, tal como se indicó, que el trabajo tendrá una primera parte teórica general sobre los autoritarismos y democracias, puesto que se considera pertinente para luego contrastar los elementos de estas categorías con el régimen político venezolano y sus implicaciones en la teoría política y los derechos humanos.

También se señala que en el artículo no se indicarán de manera detallada las fuentes normativas sobre la democracia y derechos fundamentales de Venezuela, tanto a nivel nacional como internacional, puesto que tales elementos superarían los objetivos de este trabajo, así como la extensión exigida. No obstante, en virtud de que los valores y principios democráticos, desembocan en derechos fundamentales, concretamente derechos civiles y políticos, relacionados con el sufragio universal, derechos de las minorías opositoras y principios como la alternabilidad en el poder, división de los poderes, etc., la implicación jurídica es casi obvia. Por lo tanto, en el trabajo se harán algunas breves referencias a la Constitución venezolana y al derecho internacional que reconoce, a pesar de constituir, tal como se demostrará, un gobierno autoritario.

2 Tal como se sustentará en el punto III de este trabajo y cuyo antecedente importante lo constituye Alberto Fujimori en Perú 1990-2000 [Cf. Burt, Jo-Marie (2011)].

3 O’Donnell (1996), pp. 12-15.

4 Couso (2004), p. 45. 


\section{SOBRE LOS REGÍMENES O GOBIERNOS NO DEMOCRÁTICOS}

Para esta propuesta de análisis se considerará la clasificación de aquellos tipos de gobiernos adversos a la democracia ${ }^{5}$, consistentes en: autoritarismos (personales, militares, cívico-militares, de movilización), totalitarismos y regímenes tradicionales.

\section{Autoritarismos}

Muchos autores cuando definen el autoritarismo en el ámbito político se refieren a aquellos regímenes políticos con pluralismo político limitado y no responsable, sin una elaborada ideología que lo dirija, pero con mentalidades o ideologías características; sin movilización política extensa o intensa, excepto en algunas fases de su desarrollo, y con un líder o a veces un pequeño grupo que ejerce el poder dentro de límites formalmente mal definidos, pero en realidad bastante previsibles ${ }^{6}$.

El mismo Linz ${ }^{7}$ aclara que con su definición diferencia los autoritarismos de las formas de gobierno democráticas y de los totalitarismos, pero además advierte que aprecia que su distinción con las democracias es clara; no obstante, con los totalitarismos no, por cuanto sus límites con estos son borrosos, porque los autoritarismos pueden preceder y suceder a los regímenes totalitarios.

Aspectos de la propuesta teórica sobre los regímenes autoritarios de Linz

- Es formalista en el sentido de que se concentra en la forma en que el poder se configura, ejerce, organiza y relaciona con los sectores sociales, así como también en el rol de los ciudadanos en el proceso político. Desde esta perspectiva, no atiende al contenido de los programas políticos, las políticas públicas ni los fines perseguidos en estos regímenes.

- Se refiere a regímenes y no a gobiernos autoritarios, debido a la baja especificidad de las instituciones que los componen, porque penetran sectores de la sociedad, impidiendo la expresión por la fuerza de algunos de ellos o influyendo en ellos mediante políticas intervencionistas.

5 Morlino (2004), pp.155-169.

6 LiNZ (1978), p. 12.

7 LiNZ (1978), pp. 13-14.

8 LiNZ (1978), pp. 14-15. 
- El concepto de autoritarismo de Linz, advertido por él mismo, concentra su atención en la forma en que el poder se ejerce, se organiza y se relaciona con las sociedades, en la naturaleza de los sistemas de consenso que lo mantienen y en el papel de los ciudadanos en el proceso político sin prestar atención al contenido específico de los programas políticos, los fines perseguidos, etc.

Asimismo, entre los elementos o caracteres de estos regímenes, el mismo autor señala:

- Son pluralistas, pero de un pluralismo problemático, en palabras del mismo Linz: "limitado"'. Esta limitación es jurídica o de facto, de tal manera que los grupos políticos independientes del Estado o dependientes de él, no pueden tener alguna influencia en el proceso político.

Para Morlino ${ }^{10}$ el pluralismo de estos regímenes no es responsable, ya que la coalición que comprende el partido oficial, sectores económicos, trasnacionales, eclesiásticos, sindicatos, campesinos, etc., no está comprometida con el pueblo, desde el punto de vista político-democrático, tal como ocurre en las democracias competitivas, puesto que en los autoritarismos las elecciones no tienen más que “... un significado simbólico de legitimación, expresión de consenso y apoyo a favor del régimen por parte de una sociedad civil no autónoma y controlada" 11 .

Muchos de estos regímenes, quizás con pretensiones de tener ribetes democráticos, llegan a establecer la participación política del reducido grupo de movimientos o partidos independientes, incluso impulsando su aparición, pero a pesar de esto, no queda duda alguna de que son los gobernantes los que tienen la última palabra sobre qué grupos deben existir y bajo qué condiciones.

- Contrario a lo anterior, al mismo tiempo existe un partido oficial, único o privilegiado, quizás con funciones similares a las propias del totalitarismo, pero a la vez diferente, puesto que es la unión de diversos aspectos políticos y sociales propios y dependientes del régimen.

- Tienen ideas abstractas, para cohesionar y manejar a sus seguidores y estructuras (mentalidades) donde entra lo simbólico, ciertos valores, creencias, etc., pudiendo considerarse como similares a la ideología en los totalitarismos ${ }^{12}$.

9 Linz (1978), pp. 15-16.

10 Morlino (2004), pp. 152-153.

11 Morlino (2004), p. 152.

12 Tal como se verá en el punto I.2 de este trabajo. 
- La movilización es limitada, ya que destaca la apoliticidad de los ciudadanos como consecuencia del pluralismo limitado que sostiene al régimen; no obstante, considera que, en la implantación de estos sí opera la movilización con base en una idea común guiada por un partido único, pero esta no es constante, como ocurre en los totalitarismos ${ }^{13}$.

Morlino $^{14}$ afirma que en estos regímenes la movilización no es deseada por cuanto desde el gobierno no se cuenta con la fuerza ni la eficacia en la movilización y esto fomenta, dentro de un marco de ausencia de garantías de derechos civiles y políticos, la represión política a posibles movilizaciones de sectores independientes por parte de los grupos de seguridad pertenecientes o no a la estructura militar.

- Régimen de semioposición o pseudooposición, de parte de grupos dependientes y no dependientes del régimen y en cuanto a los dependientes o relacionados con el régimen se debe a objetivos no compartidos en algún momento, diferencias en ciertas políticas, pero aceptan el mecanismo autoritario. En muchos casos, cuando sí desafían al régimen y desean mayor participación, pueden convertirse en oposición ilegal.

La oposición legal de la que se habló anteriormente es igual a la semioposición, puesto que está subordinada en su origen y desempeño al gobierno.

Asimismo, Morlino destaca dentro de los elementos propuestos por Linz ${ }^{15}$ sobre el autoritarismo, la creación e institucionalización de nuevas y diferentes estructuras políticas que lo caracterizan, siendo algunas típicas:

- Partido único, sindicatos verticales o dependientes del gobierno, organizaciones de empleadores, formas de asambleas parlamentarias para salvaguardar sus intereses, sistemas electorales particulares, juntas militares, órganos constitucionales ad hoc y otras particularidades de órganos inexistentes en el régimen precedente.

- Los dirigentes del gobierno, las autoridades, el líder o pequeño grupo que detenta el poder, se caracterizan por una gran personalización, muy visible, a veces carismático o un grupo de pocas personas que detentan de hecho los resortes del poder, estando presentes en los órganos de dirección política.

- Minimizan al derecho y uno de los fines de este, la certeza o seguridad jurídica, en efecto, "tienen límites formalmente mal definidos, pero bastante previsibles", dentro de los cuales los gobernantes autoritarios ejercitan el poder. Esto contrasta

$13 \mathrm{Al}$ respecto consultar ARENDT (1998).

14 Morlino (2004).

15 Cf. Morlino (2004) y Linz (1978). 
con la certeza del derecho propia -al menos a nivel prescriptivo- de los regímenes democráticos. En cualquier caso, tal situación, por lo común conscientemente deseada y mantenida, permite a los gobernantes ejercitar el poder de un modo más discrecional"16.

\subsection{Tipos de autoritarismos}

En cuanto a los tipos de autoritarismos, tenemos los personales, militares, cívico-militares y de movilización ${ }^{17}$.

A.- Autoritarismo personal: Dentro del marco de los elementos señalados anteriormente por Linz y Morlino, el tipo personal lo define el papel central que desempeña un líder o dictador, intemporal, no sometido a limitaciones legales, ni tampoco condicionado por grupos sociales o instituciones que lo apoyan. Es por eso que militares, grupos económicos, sindicatos, otros sectores importantes, están subordinados a él.

La justificación de este régimen obedece al personalismo, a la relación directa con el líder, quien es considerado a su vez como propietario del país; por consiguiente, en estos tipos personalismo y patrimonialismo están íntimamente vinculados.

B.- Autoritarismo militar: Tipo de régimen en el cual un sector militar de las fuerzas armadas, o varios oficiales del más alto grado, constituyen el actor político más importante.

Si dentro de ese sector militar controlador existe la presencia de un líder militar en posición preminente respecto del resto, se habla de autocracia o tiranía militar. Esto ocurre cuando ese líder militar logra dominar por completo las fuerzas armadas y gobernar completamente de manera personalista; es similar al anterior, personalista, pero del tipo militar.

Muchos de estos regímenes degeneran en cleptocracia, por la corrupción que los caracteriza, ausencia de controles, y por ese elemento personalista, donde el jefe de estado, y en este caso militar, se convierte también en dueño del país y de sus recursos ${ }^{18}$.

16 Morlino (2004), p. 8.

17 Cf. Morlino (2004), pp. 155-174.

18 Tal como se indicó anteriormente en el autoritarismo de tipo personalista. 
En este tipo de autoritarismo militar existe una oligarquía militar que controla la estructura y burocracia estatal, los negocios del Estado y hasta los sindicatos.

C.- Autoritarismo cívico-militar: Comprende una alianza entre militares profesionalizados y civiles. Los civiles pueden ser burócratas, dirigentes políticos, tecnócratas o representantes de la burguesía industrial y financiera.

En esas coaliciones existen tensiones entre ambos componentes, civiles y militares, por tener en muchos casos objetivos distintos, como también pueden existir entre ellos superposición de roles o cooperación, y no conflicto.

D.- Régimen autoritario de movilización: Es el tipo de autoritarismo más cercano al totalitarismo, porque presenta un pluralismo más limitado que los otros, la existencia de un partido oficialista con rasgos importantes de partido único y una amplia movilización, que puede desaparecer ${ }^{19}$.

En efecto, este tipo de autoritarismo se caracteriza por:

- Rol prominente del partido oficial o hegemónico, pudiendo convivir con otros partidos menores, sin que exista una verdadera competencia.

- Poseen ideologías conforme al contexto cultural del cual emergen.

- Tiene movilización, en virtud de que posee una gran articulación de estructuras políticas nacionales y locales, tanto partidarias como sociales; no obstante, puede ser que esta movilización no se mantenga en el tiempo.

\section{TOTALITARISMOS}

Es aquel tipo de gobierno o régimen no democrático en el que concurren los siguientes elementos ${ }^{20}$ :

- Concentración del poder en un líder.

- Sustitución del sistema de partidos por un movimiento de masas.

- El terror como mecanismo de dominación.

- La progresiva abolición de las libertades y derechos de la persona humana.

- Desplazamiento constante del centro del poder.

- Coexistencia del poder real y el ostensible.

- Uso de la propaganda y del sistema educativo para adoctrinar.

- Supervisión centralizada de la economía.

- Utilización del derecho, mediante la manipulación de la legalidad, con el propósito del logro de sus objetivos.

19 Ir al punto anterior: I.1, sobre los autoritarismos.

20 VARGAS (2011), p. 118. 
Todos estos elementos son advertidos por Arendt ${ }^{21}$. También destaca la autora los siguientes efectos o mecanismos de los regímenes totalitarios analizados por ella: la Alemania nazi y el gobierno comunista de Stalin, caracterizados por el manejo de las masas y el uso del terror como herramienta política ${ }^{22}$.

Estos elementos son similares en los distintos tipos de regímenes totalitarios, incluso enemistados y con ideología diferente; verbigracia, los típicos de la Alemania nazi, el fascismo y el comunismo. En efecto: "El control total de una sociedad ha obligado a sus perpetradores a recurrir casi siempre a las mismas estrategias, tácticas e incluso términos discursivos para cumplir su misión, aún si estas fueron aplicadas por regímenes que a su vez estuvieron enemistados entre sî"23.

\subsection{El manejo de las masas}

Las masas consisten, según Vargas, quien analiza a Arendt, en personas que, por su número, apatía o por ambas razones, son mayoría, pero no se hallan integradas en organizaciones profesionales, sindicatos o partidos políticos; esto porque habían sido apáticos con respecto a la militancia política y por ende no habían sido corrompidos políticamente ${ }^{24}$.

Estas masas, que se caracterizan por ser heterogéneas, van a ser presa de la propaganda y del discurso de un líder que se dirige a ellas, logrando lealtad total e incondicional al movimiento totalitario ${ }^{25}$.

La característica principal del hombre-masa no es la brutalidad y el atraso, sino su aislamiento y su falta de relaciones sociales normales; por lo tanto, el verdadero objetivo del gobierno totalitario es la organización de las masas de los individuos dispersos, aislados, atomizados. De hecho, fomenta el aislamiento para impedir la asociación, la agrupación, interacción, es decir, destruye las capacidades políticas para que el individuo sea parte de una masa: un grupo de individuos no pensantes ${ }^{26}$.

\footnotetext{
21 ARENDT (1998).

22 VARGas (2011), pp. 119, 120.

23 BRUM (2011) p. 5.

24 Vargas (2011), p. 118.

25 VARGas (2011), pp. 118-119.

26 AREndt (1998), pp. 380-382.
} 
El conocimiento del hombre masa, su visión de las cosas, tiende a no ser regulado por la experiencia, por el contacto con la realidad, por el choque con la realidad del mundo, sino solamente por la coherencia con la ideología que le han impuesto 27.

\subsection{El uso del terror para el sometimiento político}

El terror por la eliminación de la persona humana es posible en estos regímenes, puesto que consideran al hombre como superfluo. Eso Arendt lo desprende reflexionando sobre las experiencias en los campos de concentración nazis, refiriéndose a que la supresión de la vida humana es un hecho normal, irrelevante, tan impersonal como el aplastamiento de un mosquito. Cualquiera puede morir como resultado de la tortura sistemática o de la inanición o porque el campo esté repleto y sea preciso liquidar el sobrante o innecesario material humano ${ }^{28}$.

Es decir, se elimina la importancia del hombre, su dignidad; el hombre sobre el cual recae el terror no es más que otro integrante impersonal de la masa, el hombre masa, en este sentido considerado como enemigo.

Los gobiernos totalitarios nunca abandonan el uso del terror, ni siquiera cuando logran sus objetivos psicológicos. Su verdadero horror estriba en que reinan sobre una población completamente sometida ${ }^{29}$, bien sea adoctrinada o privada de libertad, yendo, en palabras de Brum, “... a los extremos más lejanos de violencia y represión"30.

Arendt considera que ese terror consiste en la existencia de un mal radical ${ }^{31}$, inefable, utilizado para la dominación de toda la población: mediante la eliminación de oponentes, reales, potenciales o imaginarios, y, asimismo, el logro mediante el temor de la adhesión completa de la misma masa compuesta por hombres sin razón, que no cuestionan la realidad, completamente adoctrinados, solo juzgando todo por la ideología que les ha sembrado el líder.

27 Arendt (1998), pp. 378-380.

28 AREndt (1998), pp. 372-375.

29 Arendt (1998), pp. 382-383.

30 BRUM (2011), p. 6.

31 Arendt (1998), pp. 380-384. 


\subsection{El uso abusivo del derecho}

Este es un rasgo del totalitarismo destacado por Vargas ${ }^{32}$. En efecto, en los regímenes totalitarios se establecen leyes para dar un manto de legalidad a las prácticas de dominación, terror, etc. Esto es más evidente en la Alemania nazi que en el comunismo de Stalin.

El régimen nazi se valió de la legalidad imperante para llegar al poder, manipulándola, para luego establecer leyes demoledoras contra los derechos humanos que blindaban su maquinaria de represión, para que los que protestaran pudieran ser enjuiciados como agitadores, criminales, desestabilizadores, según las nuevas leyes del sistema nacionalsocialista ${ }^{33}$.

\section{LOS REGÍMENES NO DEMOCRÁTICOS TRADICIONALES}

Presentes en ciertos países como Arabia Saudita y los Emiratos Árabes ${ }^{34}$, los cuales tienen como base de legitimación la naturaleza patrimonial y la presencia de una monarquía absoluta (sultanística), que domina a sus colaboradores mediante miedos y recompensas. Asimismo, son regímenes sin limitaciones legales ni ideológicas en la ejecución de sus acciones, que por ello son en sí mismas arbitrarias, de allí que el ejército y las policías juegan un papel preponderante para garantizar la represión ante cualquier movimiento disidente. Se observa un uso del poder en forma particularista, es decir, para fines privados, beneficiando a élites y a instituciones tradicionales, como la monarquía.

Ahora bien, a estos gobiernos no democráticos, autoritarios y totalitarios, se enfrentan las propuestas democráticas contemporáneas, recogidas muchas de ellas en los ordenamientos jurídicos de la mayoría de los países del mundo occidental.

\section{Autoritarismos y POPUlismos}

Existe una vinculación entre los gobiernos populistas con un gobernante personalista incluso elegido democráticamente, que puede eventualmente dirigirse hacia el autoritarismo, es por eso que en este análisis se abordarán algunas

\footnotetext{
32 VARGAS (2011), pp. 121-122.

33 VARGas (2011), pp. 122-125.

34 Morlino (2004), p. 22.
} 
nociones del populismo, muy relacionado con los gobiernos autoritarios actuales en Latinoamérica.

Conforme a Vallespín ${ }^{35}$, el populismo es una lógica de acción política de los gobiernos caracterizada por los siguientes elementos:

- Se generan luego de un brusco cambio social consistente en modernización, industrialización, sociedad de masas, migraciones, como causas negativas frente a lo que se reacciona para resolver esos problemas.

- Se presenta una política de cuestionamiento dramática que provoca en la sociedad la urgencia de resolver la situación en cuestión, a los fines de restaurar un orden de convivencia, paz, etc., subvertido por las causas señaladas anteriormente.

- Se apela al pueblo, que es víctima de la problemática que se quiere atacar, bien sea extraños, migrantes, élites, etc.

- La utilización de un antagonista para articular el discurso con el pueblo o víctima: las élites económicas, los migrantes, "los de arriba", etc.

Aquí Vallespín ${ }^{36}$ resalta que el populismo engrandece o ensalza la parte agraviada mientras denigra y ofende al enemigo que presuntamente provocó la situación problemática, y al mismo tiempo manipula emocionalmente al pueblo, generándole rabia o resentimiento contra el sector antagonista.

- Es antielitista y antipluralista.

- El discurso es simplificador en las razones para considerar a algún sector como enemigo causante de la situación problemática que afecta a toda la sociedad.

- Entran en conflicto con los sectores democráticos que critican los elementos anteriores, por ser no razonables, antidemocráticos, no tolerantes y constituir ataques al "enemigo"; por eso es usual que el populista confronte también a los medios de comunicación, televisión, prensa, etc.

Si se realiza un cruce entre los caracteres del autoritarismo anotados arriba y los elementos del populismo, se aprecian bastante similitudes o al menos elementos relacionados, factores del populismo que fácilmente pudieran desembocar en autoritarismos. Es el personalismo presente en ambas categorías políticas, que en el caso del populismo actúa para enfrentar la crisis provocada por el presunto enemigo, en muchos casos mediante medidas contrarias al derecho, a los derechos fundamentales. Se advierte entonces que el populista, al igual que el autócrata, por

35 Vallespín (2017), pp. 8-9.

36 Vallespín (2017), p. 8. 
su personalismo dominante, no tiene límites legales, además de contar también con un pluralismo limitado.

Es por eso que O'Donnell ${ }^{37}$ denomina a los sistemas políticos personalistas, donde el gobernante ha sido elegido por votación popular, "democracia delegativa”, término referido a aquellas democracias que funcionan bajo la premisa de que quien gane una elección presidencial tendrá la facultad de gobernar como él lo considere apropiado, limitado solo por la dura realidad de las relaciones de poder existentes y por el período establecido constitucionalmente.

Los caracteres de la democracia delegativa según el mismo autor son los siguientes ${ }^{38}$ :

- El presidente es la "encarnación del país", principal custodio de los intereses del pueblo, constituye una figura paternal a quien le corresponde encargarse de toda la nación.

- Las políticas de su gobierno no necesitan estar relacionadas con las promesas de su campaña, porque ha sido autorizado (delegado) para gobernar como él lo estime conveniente.

- Su base política es un movimiento político.

- El presidente se sitúa a sí mismo sobre los partidos políticos y los intereses organizados.

- Los parlamentos y los tribunales de justicia constituyen un estorbo y son de alguna manera minimizados en su papel, el cual es irrelevante, por las ventajas en la comunidad nacional e internacional de ser un presidente democráticamente elegido.

- También la rendición de cuentas, que constituye un elemento de la democracia medido por las doctrinas presentes en los estudios de la calidad democrática ${ }^{39}$, implica un obstáculo a la plena autoridad que se le ha delegado al presidente.

- En las democracias delegativas, las elecciones democráticas son muy importantes, pero después de estas los votantes (quienes delegan) deben convertirse en una audiencia pasiva, para que aclame lo que el presidente decida y haga.

- El presidente, a quien se le ha "delegado todo", ignora las resistencias a sus políticas provenientes del congreso, los partidos políticos, los grupos de interés o las multitudes en las calles.

37 O’Donnell (1994), p. 12.

38 O’Donnell (1994), pp. 12-15.

39 Por ejemplo, el estudio The Economist Index, referido en el punto III de este trabajo. 


\section{SOBRE LA DEMOCRACIA}

\section{NOCIONES DE DEMOCRACIA}

La democracia sigue vigente, porque además de ser una forma de gobierno o de dominación política, es una forma de vida del conglomerado social y de los individuos que lo componen, lo cual está vinculado estrechamente a la cultura política de los ciudadanos, es decir, cómo se piensa, qué orienta el actuar del hombre en la sociedad, la forma en que se quiere que las instituciones gubernamentales funcionen y se articulen con la ciudadanía, la participación política y social, entre otras.

La democracia es opuesta al autoritarismo o cualquier forma de gobierno personalista o arbitrario, o dictadura; es contraria a la autocracia, a la tiranía, a la aristocracia y oligarquía ${ }^{40}$; en fin, al gobierno de uno o pocos o al gobierno de un solo sector, puesto que es el gobierno de muchos, de distintos sectores, cuyas instituciones principales son en un principio el sufragio universal y la regla de la mayoría en la toma de decisiones.

Razonablemente, al hablar de gobierno de muchos, de numerosos sectores, pareceres, sentires, intereses, etc., el pluralismo aparece como un elemento primordial. Se aprecia entonces que la democracia comprende una dialéctica interesante, poderosa, entre la regla de la mayoría y el respeto a las minorías.

La democracia en la tradición liberal es eso mismo, libertad, el sistema inspirado en poder hacer todo aquello que vaya en beneficio del hombre, sin más restricciones que las constatadas por la razón humana que afecten al mismo individuo. En esta tradición liberal, existen instrumentos normativos: cartas de derechos y constituciones, que formaron gobiernos con sujeción a los derechos del hombre, es decir, los derechos humanos o fundamentales, mayormente derechos de libertades, pero con un asomo de igualdad, puesto que la participación se amplía a todos o casi todos, sobre todo a las personas afectadas por las decisiones de un pueblo o colectividad ${ }^{41}$.

Una de las nociones más respetadas sobre la democracia es la de Bobbio, lo que él denomina una "noción mínima de democracia". El autor italiano afirma: "... cuando se habla de democracia, en cuanto contrapuesta a todas las formas de gobierno autocrático, es considerarla caracterizada por un conjunto de reglas

40 Los cuales se analizaron en el punto anterior.

41 Bоввіо (1986), pp. 24-27. 
(primarias o fundamentales) que establecen quién está autorizado para tomar las decisiones colectivas y bajo qué procedimientos" ${ }^{\prime 2}$.

De esa definición mínima parten tres elementos fundamentales de la democracia:

- Las personas autorizadas para tomar las decisiones obligatorias dirigidas a todo el grupo, deben ser la mayor cantidad posible del mismo, lo que en las democracias más recientes constituyen todos los adultos, hombres y mujeres.

- Que el procedimiento para decidir consista en la regla de la mayoría.

- La presentación de alternativas u opciones reales y que los miembros del grupo estén en condiciones de decidir entre una y otra.

Para la realización de esta última condición, Bobbio plantea que es necesario que, a quienes deciden y opten por ser elegidos, les sean garantizados los derechos de libertad de opinión, reunión, asociación, etc.; es decir, aquellos derechos que constituyen la base del Estado liberal de derecho. El autor enfatiza en lo indispensable que es el Estado liberal para la permanencia de la democracia, y viceversa, la permanencia de la democracia para el aseguramiento del Estado liberal; en este sentido asegura:

Es improbable que un estado no liberal pueda asegurar un correcto funcionamiento de la democracia, y por otra parte es poco probable que un Estado no democrático sea capaz de garantizar las libertades fundamentales. La prueba histórica de esta interdependencia está en el hecho de que el Estado liberal y el Estado democrático cuando caen, caen juntos ${ }^{43}$.

No obstante, Bobbio posteriormente amplía estos derechos e incluye los derechos sociales como garantías para el ejercicio de los derechos de la tradición liberal, propios de la democracia, como educación, salud, trabajo, etc. Es una combinación de las garantías propias del liberalismo con las conquistas sociales reivindicadoras de sus derechos, la protección de los débiles y la igualación de los desiguales ${ }^{44}$.

Por otra parte, las concepciones de democracias más aceptadas constituyen la propuesta contemporánea de $\mathrm{Dahl}^{45}$, compuesta por un grupo de instituciones o requisitos que forman la democracia representativa en un marco de diversidad

42 Bоввіо (1986), p.14.

43 Воввіо (1986), р. 16.

44 Para abundar más al respecto, se sugiere la consulta de Bovero (2006): "El liberal-socialismo para Bobbio y para nosotros".

45 DAHL (1992), pp. 266 y 267. 
(la poliarquía o democracia pluralista), que,a pesar de versar sobre la tesis de la representación, conserva vigencia en la actualidad, puesto que esta forma de organización estatal sigue siendo necesaria por la complejidad de la sociedad moderna, cuestión que no desdeña para nada la insuficiencia de la democracia representativa por el distanciamiento que puede ocurrir de los funcionarios electos, al no considerar las necesidades de sus mandantes o electores.

En la propuesta de Dahl ${ }^{46}$, un régimen es democrático siempre y cuando de manera concurrente y efectiva, es decir, no solo normativamente sino realmente, estén presentes las siguientes instituciones, derechos o libertades, que en gran parte coinciden con las propias del Estado liberal que propone Bobbio:

- Control por parte de los funcionarios electos de las decisiones en materia de políticas públicas.

- Los funcionarios electos son elegidos mediante el voto en elecciones libres, limpias, imparciales y regulares o periódicas.

- Sufragio inclusivo para prácticamente todos los adultos.

- Derecho a ocupar cargos públicos a prácticamente todos los ciudadanos adultos.

- Libertad de expresión de los ciudadanos, sin correr el peligro de sufrir castigos severos en cuestiones políticas amplias que abarcan la crítica a los siguientes aspectos: los funcionarios públicos, el gobierno, el régimen, el sistema socioeconómico y la ideología prevaleciente.

- Diversidad de fuentes de información, que deben existir y estar protegidas por la ley.

- Autonomía asociativa, consistente en el derecho de los ciudadanos a constituir asociaciones para la salvaguarda de sus derechos e intereses, como los partidos políticos y grupos de presión, independientes del Estado.

Es necesario destacar que la propuesta de Dahl es descriptiva y normativa a la vez, por ser, por un lado, muy realista en muchas sociedades -fue comprobada por Tocqueville en su obra Democracy in America, publicada en 1835, y por el mismo Dahl en su obra Who goberns?, de 1962-, y por otro lado, es valorativa, es lo que se desea exista en una democracia para ser considerada como tal, resaltando al pluralismo como elemento fundamental.

Se reitera que esto es democracia: diversidad, oposición, alternativa, opción distinta a la oficial, lo cual implica razonablemente el respeto a la minoría, luego

46 DAHL (1992), p. 267. 
que se aplica la regla de la mayoría, porque eso es lo fundamental del método democrático, la posibilidad de que una minoría pueda eventualmente convertirse en mayoría. Para ello, debe evitarse que la mayoría pueda limitar, restringir o hacer desaparecer la minoría ${ }^{47}$.

Claro está, este respeto a la minoría no debe significar que esta gobierne, precisamente en la democracia la legitimidad de origen (el derecho a mandar) lo tienen los funcionarios electos, es decir, los elegidos mayoritariamente por el pueblo, que es la primera característica de la poliarquía según Dahl ${ }^{48}$, señalada más arriba: control por parte de los funcionarios electos de las decisiones en materia de políticas públicas.

De esta manera, la democracia en el sentido contemporáneo sería una síntesis entre la mayoría y minoría(s), lo que implica el respeto a los derechos humanos o fundamentales de esa minoría, de esa oposición, para que pueda tener la posibilidad de llegar a ser mayoría, porque la democracia se opone a dictadura, al ejercicio por tiempo prolongado en el poder de una sola opción política. Es por ello que la alternabilidad ${ }^{49}$ es esencial también para un régimen democrático.

Los derechos de esa minoría para que se garantice la alternabilidad de esa democracia son los derechos fundamentales y, dentro de estos, los políticos o los más relacionados con los políticos (civiles), ya señalados por el mismo Dahl y que se indican de nuevo: sufragio universal, donde participen todos los partidarios o no del partido en el ejercicio en el poder; libertad de expresión e información a través de ciudadanos no coaccionados y de fuentes alternativas; libertad de asociación de grupos distintos a la opción política del gobierno, en un marco de elecciones libres, pulcras, periódicas y competitivas; el sufragio pasivo, lo cual trae consigo la prohibición de limitaciones arbitrarias a este derecho.

Para Gorczevski y Muller50, la democracia, denominada por ellos "principio democrático", comprende dos grandes postulados: el de la democracia representativa (elecciones periódicas, órganos representativos, partidos políticos, división de los poderes) y el postulado participativo, que implica la intervención de los ciudadanos en los procesos decisivos, en la formación de la decisión, el control de

47 Ferrajoli (2008).

48 Dahl (1992), p. 267.

49 A lo largo de los puntos III y IV de este trabajo, se abundará sobre la alternabilidad, al comentar el régimen político venezolano.

50 Cf. Gorczevski y Muller (2010), pp. 17-19. 
los procesos, etc., resaltando, al igual que otros autores, como Sartori ${ }^{51}$, que es en el pueblo en quien recae la fuente de poder, la soberanía, que, como se explica en los postulados mencionados, la puede ejercer directamente, participativamente $o$ mediante los representantes elegidos, es decir, en forma representativa.

\section{LA DEMOCRACIA Y EL PODER JUDICIAL (LA DEMOCRACIA CONSTITUCIONAL)}

La doctrina política no solo ha avanzado en el establecimiento de los elementos o requisitos para que un gobierno sea democrático, sino en un aspecto que constituye un elemento fundamental para mantenerlo, el Poder Judicial, el cual debe garantizar el mantenimiento de los valores, principios y derechos fundamentales de la democracia, siendo esto evidente tanto doctrinaria como normativamente, es decir, deben estar presentes en cartas democráticas, tratados internacionales, constituciones, etc.

Constituye el poder judicial el soporte del mantenimiento y consolidación de la democracia, por ser uno de los garantes de esta, por asegurar sus derechos, evitar que el jefe de Estado se convierta en un autócrata sin frenos legales, es decir, actúe ajustado a la legalidad y al Estado de derecho. Esta relación es lo que ha generado la categoría democracia constitucional.

La democracia constitucional es el reconocimiento en primer lugar de los valores de la democracia en su sentido tradicional (la regla de la mayoría); en segundo lugar, la libertad fundada en los derechos de los individuos, y, en tercer lugar, el marco normativo creado y aplicado para garantizar estas valoraciones en una sociedad. Es una combinación difícil de hacer, puesto que son principios contrapuestos que traducen, por un lado, el derecho a las decisiones de los órganos electos y, por otro lado, las decisiones de órganos minoritarios (tribunales) para garantizar los derechos individuales, los civiles y políticos ${ }^{52}$.

$\mathrm{Nino}^{53}$ plantea que la democracia constitucional basada en el paradigma liberal consiste en una democracia limitada, puesto que asegura que ciertos derechos de las minorías no deben ser violados, incluso por decisiones mayoritarias, esto es, debido a que están fuera del proceso democrático y son protegidos a su vez

51 Cf: SARTORI (1988).

52 NiNo (2003), p. 13-29.

53 Nino (2003), p. 19. 
por mecanismos jurisdiccionales y no electorales, como el control judicial de la constitucionalidad de las leyes.

La democracia constitucional establece límites al principio democrático o mayoritario, en virtud de que las decisiones de la mayoría se encuentran sometidas a una reserva fundamental, a la correspondencia de estas decisiones con la Constitución ${ }^{54}$.

La democracia constitucional entonces es la prevista en las constituciones de tradición liberal desde finales del siglo XVIII, puesto que es eso, la democracia liberal hecha norma con la finalidad de garantizar los derechos y libertades, pero con un sistema judicial consolidado, para afianzar esos derechos humanos a todos los ciudadanos, frente a cualquier arbitrariedad por parte del Estado.

La influencia de la tradición liberal se mantiene en las constituciones y en la democracia desde Rousseau con su contrato social en 1762, Mill en 1859 y más recientemente Dworkin en 197755 . No obstante, esa evolución histórica de los derechos humanos abarcó también los derechos sociales mediante cambios políticos y constitucionales desde principio del siglo XX, es decir, comprendió también los derechos de prestación por parte del Estado, para superar las violaciones de los órganos del poder público a los derechos fundamentales de los ciudadanos previstos en la norma suprema.

¿Y qué más democrático que ese poder constituyente expresado a través de elecciones mediante la participación del pueblo? Sobre todo elecciones donde se respete el pluralismo, es decir, en las cuales existan varias opciones o propuestas sobre cómo debe ser la filosofía política que inspirará al derecho y al Estado en cada sociedad, o, lo que es lo mismo, la Constitución o pacto político como expresión jurídica de un país.

El poder judicial producto de ese poder constituyente es el llamado a proteger los derechos fundamentales, es decir, el llamado a asegurar las reglas del proceso democrático: amplitud de la participación en la discusión de los asuntos a resolver entre los afectados por la decisión que se tome; la libertad de expresarse que tienen los participantes de hacerlo por sí mismos en una deliberación; igualdad de condiciones bajo las cuales la participación se lleva a cabo, y que las propuestas sean debidamente justificadas ${ }^{56}$.

54 Hassemer (2009).

55 DwORKIN (1977).

56 García de Enterría (2001) y Nino (2003). 
Es un espacio abierto, un juego de posibles alternativas que permita a una tendencia la oportunidad de ser mayoritaria, evitando la petrificación de un sistema político. Para ello es necesario el resguardo del proceso democrático, mediante los tribunales que deben garantizar sus condiciones ${ }^{57}$.

La democracia constitucional al establecer límites a la regla de la mayoría, más que contrariar a la democracia, por el contrario, resguarda su verdadero sentido, puesto que la regla de la mayoría en una democracia lleva consigo de manera intrínseca el principio de alternabilidad en el ejercicio del poder, y por ende el respeto de las minorías ${ }^{58}$, lo cual reclama un clima institucional en que la libertad de expresión y la participación política se encuentren amparadas, derechos constitucionales que requieren la actuación de la jurisdicción constitucional.

Cuando se habla del respeto a la minoría en una democracia, los autores lo hacen en el sentido convencional, es el respeto a la oposición política que en ese momento no está en el poder porque en la última elección no salió favorecida por la mayoría del cuerpo electoral y se ha traducido en minoría en un cuerpo parlamentario y en ausencia de gobierno en un cargo del poder ejecutivo; es el respeto a la oposición a sus derechos políticos para que pueda llegar a ser mayoría y se pueda dar la alternancia en el poder de quererlo así la mayoría de ciudadanos de un país. Es decir, esa minoría u oposición puede en un momento dado ser una mayoría potencial, pero que no se ha materializado formalmente en cargos y escaños, puesto que no ha llegado el momento del sufragio.

Debe entonces una democracia dar garantías para que esta fuerza política pueda, de quererlo el cuerpo electoral, ser gobierno, promoviéndose de esta manera la alternancia en el poder y, asimismo, la democracia pueda efectivamente oponerse a la instauración de cualquier autoritarismo o forma indefinida de permanencia en el poder e igualmente de cualquier práctica que pueda fomentarlo.

Tribunal constitucional y democracia no estarían entonces contrapuestos, por cuanto aquel sería el órgano que haga efectivo los derechos constitucionales que configuran el régimen democrático establecido en el texto fundamental; no se opone a la democracia, sino que por el contrario la materializa, la hace efectiva, claro está, siempre y cuando sus decisiones vayan en provecho de los valores, principios democráticos y derechos políticos de todos los sectores: pluralismo, participación, libertad de expresión e información, de organización, entre otros.

57 García de Enterría (2001) y Vásquez (2001).

58 CASAl (2009), pp. 159-164. 
De la misma manera, Cazor ${ }^{59}$, advirtiendo esa vinculación entre Constitución, su garante, el Tribunal Constitucional, y, asimismo, la democracia, afirma que existe un engranaje entre las categorías (afinidades), puesto que el poder judicial tiende a limitar el poder del Estado para garantizar la libertad individual y social, garantías y componentes de la democracia, dada la vinculación estrecha entre liberalismo, derechos y libertades que protegen los órganos jurisdiccionales, los que constituyen la esencia de la democracia ${ }^{60}$.

\section{EL NEOAUTORITARISMO EN LA REGiÓN LATINOAMERICANA (EL CASO DE VENEZUELA)}

Existen varios teóricos políticos que se han dedicado a explicar los procesos mediante los cuales se llega a la democracia o también se produce inestabilidad en esta, y los factores que pueden llegar incluso a debilitar tanto las democracias que emergen, haciéndolas transitar a formas próximas a los autoritarismos y hasta totalitarismos ${ }^{61}$.

Los referidos autores han comentado sobre las causas que generan el debilitamiento y la inestabilidad en las democracias deterioradas o en consolidación, refiriéndose a limitaciones en el acceso al poder, falta de participación real de las minorías, inequidades sociales, pobreza, entre otros ${ }^{62}$.

En el caso de los nuevos movimientos con tendencias autoritarias, emergieron en Latinoamérica como reacción a los ajustes neoliberales que privilegiaron la eficacia económica sobre la justicia social, profundizando las desigualdades, es cuando movimientos de tendencia socialista, basados en la bandera de las reivindicaciones de los excluidos, la crítica a la pobreza, etc., toman fuerza e incluso llegan al poder mediante elecciones democráticas. Tales son los casos de, entre otros países, Venezuela, Bolivia, Nicaragua, Brasil, Uruguay, Ecuador, Paraguay ${ }^{63}$.

59 CAzor (2007), pp. 55-68.

60 No obstante, tal como se indicó en el punto II.1, Bоввіо agrega también a los elementos de liberalismo los derechos sociales como esenciales de la democracia.

61 Véase: el mismo MorLino (2004), analizado al principio de este trabajo, y asimismo: DAHL (1992), LinZ (1987), ZovatTo (2017), entre otros.

62 Para mayor abundamiento sobre estas causas, véase Santana Castillo (2008), Zovatto (2017), Benítez y GonzÁlez (2016), y en cuanto a los estudios precisos sobre Chávez en Venezuela, recurrir entre otros autores a Rodríguez Rojas (2010), BeníteZ y GonZÁlez (2016) y Uharte (2008).

63 Lo que explica el surgimiento de Hugo Chávez en Venezuela, Evo Morales en Bolivia, Daniel Ortega en Nicaragua, Felipe Mujica en Uruguay, Lula en Brasil, Rafael Correa en Ecuador y Lugo en Paraguay, 
El caso de Venezuela es el que se analiza en este estudio, considerando que en este país los rasgos autoritarios son más pronunciados, a pesar de consagrar en su carta magna los elementos propios de un régimen democrático, previstos en valores, principios y normas tanto en el ámbito interno como en el internacional ${ }^{64}$.

\section{El caso de Venezuela: ¿Neoautoritarismo?}

Contrario a lo previsto en el ámbito formal o normativo, se constituye en este país una forma de gobierno no democrática, por cuanto su régimen político, y el sistema político en general, se caracteriza por un gran personalismo, limitaciones excesivas a los derechos civiles y políticos, poder judicial al servicio del jefe de Estado, que le ha facilitado a este el camino a la reelección indefinida, violentando la alternabilidad, que constituye uno de los grandes pilares de la democracia, puesto que este principio es el que evita -es decir, previene- la entronización de un líder de manera indeterminada en el poder, con sus negativas consecuencias, colonización de los otros poderes como el judicial, el órgano electoral principal, entre otros.

En efecto, Venezuela se encuentra entre los países peores ubicados en Latinoamérica en calidad democrática ${ }^{65}$ y presenta, entre otros aspectos comunes y adversos a la democracia ${ }^{66}$, los siguientes:

- Debilidad de las instituciones de la democracia representativa (Congreso y partidos políticos).

- Excesivo presidencialismo y fiebre reeleccionista.

- Alto niveles de corrupción y poca o nula política de rendición de cuentas.

no todos con tendencias autoritarias o al menos del mismo tenor o calibre y en algunos casos democracias profundizadas, como Mujica en Uruguay.

64 En las constituciones correspondiente a Venezuela (Constitución de Venezuela de 1999), se consagran los principales valores, principios y derechos propios de un régimen democrático y, asimismo, se otorga pleno reconocimiento de las normas internacionales en materia de derechos humanos. Al respecto, véase su parte relativa a los principios y su parte dogmática en general: artículos $1^{\circ}$ al 129.

65 Cf. The Economist Democracy Index (2016 y 2017). En efecto, Venezuela en el informe de calidad democrática durante 2016 ocupó los últimos lugares de los países híbridos, con elementos democráticos frágiles y elementos autoritarios, y en el 2017, este autoritarismo se constató agravado por cuanto fue ubicada propiamente entre los regímenes autoritarios.

66 Cf. GarCía OÑoro (2012), pp. 22-31. Además, en esas páginas el autor se refiere también a otros países latinoamericanos con algunos elementos personalistas que pudieran ser también autoritarios como Argentina, Ecuador, Bolivia y Colombia. 
- Ataques al poder judicial cuando las decisiones son adversas y, asimismo, el logro del control de este, judicializando la política, lo cual es evidente en Venezuela ${ }^{67}$.

- Otros aspectos significativos de estos regímenes personalistas con rasgos autoritarios, que comprenden el caso Venezuela.

- Se aprovechan de la existencia de una democracia mínima ${ }^{68}$ para llegar al poder.

- Centralización y concentración del poder en el presidente de la República.

- Debilidad del poder legislativo y judicial para limitar el poder ejecutivo y frenar las arbitrariedades (desinstitucionalización del poder).

- Líderes que surgen de severas crisis, como en los países mencionados, por injusticia social, planes neoliberales en los 80 y 90, entre otros.

- Creen que el pueblo les ha dado el poder para decidir lo que sea ${ }^{69}$, por eso su falta de limitación por el derecho y la consulta popular, salvo las elecciones presidenciales.

- Reducción de condiciones electorales para que las elecciones no sean imparciales.

- El jefe de Estado actúa de forma paternalista, directa y sin intermediarios ante sus seguidores.

- Establece leyes que limitan libertades civiles y políticas.

- Ataca e ignora a los grupos opositores, por mucha representación que tengan; solo toma en cuenta los sectores políticos y sociales penetrados por el gobierno y su partido.

Estos aspectos generan en Venezuela lesiones a derechos civiles y políticos como el debido proceso, el sufragio pasivo, libertad de expresión y manifestación, tal como ocurre y se ha evidenciado para controlar el poder judicial ${ }^{70}$ :

- Aprobación de reformas constitucionales destinadas a dejar sin efecto decisiones jurisprudenciales o a excluir de la jurisdicción de dichas cortes ciertos asuntos de interés gubernamental.

\footnotetext{
67 Sobre este aspecto se sugiere la consulta de CHACín (2016): “Consideraciones sobre la democracia judicial: El caso venezolano", pp. 54-60.

68 Definida por Boвbio (1986) y explicada en el punto II.1 de este escrito.

69 Tal como se indicó anteriormente cuando se comentó a O'DONNELl y su propuesta de la democracia delegativa (cf. introducción de este trabajo).

70 Benítez y GonzÁlez (2016), pp. 44-48.
} 
- Implementación de planes de recomposición de los integrantes de la corte para elegir jueces leales al gobierno.

- Aprobación de nuevas constituciones (siguiendo los requisitos procesales en los cuales estos tribunales tienen un papel politico menos protagónico debido a una disminución sensible de sus funciones).

Lo que para los referidos autores constituye el "constitucionalismo abusivo", consistente en que, detrás del uso de mecanismos previstos constitucionalmente, se esconden propósitos autoritarios. Es por eso que, aunque aparentemente el régimen político del Estado pareciese ser una democracia constitucional, realmente lo que existe es el control de un partido y/o un líder popular debido a la ausencia real de mecanismos de equilibrio y contrapesos ${ }^{71}$.

Benítez y González ${ }^{72}$ explican, en el caso de Venezuela, la forma en que se ha instalado el chavismo en el poder, por ser quizás el autoritarismo más marcado y que ha influido en el resto: Nicaragua y Bolivia, con la misma ideología, el mismo discurso en favor de los excluidos, haciendo una narración que comprende los aspectos principales de cómo ese régimen controló al poder judicial y hoy es la herramienta de sus arbitrariedades.

Las estrategias utilizadas en Venezuela para el control del poder judicial, según los señalados autores, consisten en:

- Presión popular para que el Tribunal Supremo de Justicia decidiera sobre asuntos claves en favor del poder ejecutivo.

- Control del poder legislativo, quien nombró a la mayoría de jueces con tendencia ideológica similar al sector oficialista.

- Para asegurar aún más a cualquier juez disidente, destituyó a los que decidieran adversamente, mediante orden dada al poder legislativo, controlado por el jefe de Estado.

- Por el mismo motivo anterior, se estableció la Ley Orgánica del Tribunal Supremo de Justicia de 2004, mediante la cual se aumentó significativamente el número de magistrados, que fueron nombrados aún más afines al gobierno, incluso a aquellas personas que hasta ese momento ostentaban cargos oficiales y partidistas (parlamentarios, ministros, dirigentes de partido).

71 Tal como lo describe García Oñoro (2012), pp. 22-31.

72 Benítez y González (2016), pp. 53-56. 
- Esto le garantizó la aprobación de medidas arbitrarias como la reelección indefinida en 2009 , a pesar de haber sido rechazada en un referendo consultivo en 200773 .

Aunado a lo expuesto, un aspecto crucial en la colonización del poder judicial $^{74}$ está marcado por la violación fraudulenta de los mecanismos constitucionales (parlamentarios) establecidos en los artículos 264 y 270 de la carta magna venezolana, para designar a los magistrados, lo cual lo decide fundamentalmente el Comité de Postulaciones Judiciales, compuesto por ONG independientes, sin participación de los diputados o parlamentarios, ya que estos solo elegían al final por mayoría calificada la terna independiente que generaba el referido comité, luego de que este hiciera un análisis riguroso de credenciales e independencia.

Tal como lo establece la carta magna venezolana, la participación de los diputados es reducida, solo al final, cuando ya la terna de postulados a ser magistrados de Tribunal Supremo de Justicia es decidida previamente y con criterios de competencia, ética e independencia por el Comité de Postulaciones, integrado por ONG independientes.

Frente a este diseño constitucional adecuado, los parlamentarios, violentando la Constitución vigente de 1999, se hicieron parte del Comité de Postulaciones, lo que generó que las listas de magistrados emitida por este órgano, para ser confirmada por el parlamento, ya estaba politizada, compuesta por jueces dependientes del ejecutivo y su partido ${ }^{75}$.

\footnotetext{
$73 \mathrm{Al}$ respecto consultar Martínez, Eugenio (2007) en: http://www.efemeridesvenezolanas.com/sec/his/ id/119/?show=1, sitio web: efemeridesvenezolanas.com, consultado el 27.2.2017, donde se indica el rechazo a la propuesta de la reforma de la reelección indefinida en 2007 y, asimismo, las decisiones cuestionables de la Sala Constitucional del Tribunal Supremo de Justicia declarando la constitucionalidad de la propuesta de reforma en cuatro decisiones, a pesar de haber sido rechazada en el año 2007: A) Sentencia de fecha 29.4.2008, Sala Constitucional del Tribunal Supremo de Justicia, ponente: Luisa Estella Morales, Expediente No 2008-0341, caso: Luis Hueck Henríquez. B) Sentencia de fecha 3.2.2009 de la Sala Constitucional del Tribunal Supremo de Justicia, ponente: Francisco Carrasquero, Exp. No 08-1617, caso: Fundación Verdad Venezuela; Exp. No 08-0341. C) Sentencia de fecha 3.2.2009, ponente: Francisco Carrasquero, Exp. No 081611, caso: Óscar Arnal. D) Sentencia de fecha 14.7.2009, ponente: Arcadio Delgado, Exp. No 09-0165, caso: Fundación Orión, Derechos Civiles y Militares.

74 No señalado por BeníteZ y GonZÁlez (2016).

75 Para mayor abundamiento en esta estrategia fraudulenta del poder ejecutivo para asegurar la integración del máximo tribunal de justicia de Venezuela con jueces pertenecientes al gobierno y su partido, consultar: Organizaciones sociales de derechos humanos exigen suspender la designación de magistrados y magistradas del Tribunal Supremo de Justicia. En: Comunicación Continua. Venezuela. Publicado vía digital el 10.12.15, consultado en mayo de 2018 y disponible en el siguiente enlace: http://comunicacioncontinua.com/54357-2/.
} 
Aunado a esto, imposibilidad del ciudadano venezolano de acudir a la Corte Interamericana de los Derechos Humanos en defensa de sus derechos. En efecto, en Venezuela, a pesar de contemplar en su carta magna en el artículo 31 la posibilidad de los ciudadanos de acudir a organismos internacionales de derechos humanos regulados por tratados internacionales ratificados por la República, esto es negado en la realidad, puesto que la Convención Americana de Derechos Humanos fue denunciada en septiembre de 2012 por el presidente de la época, Hugo Chávez Frías, y puesta en vigor esta denuncia el 10 de septiembre de $2013^{76}$, lo cual significa un atraso gigantesco en materia de derechos humanos para esta nación, lo cual es otra circunstancia que fomenta el avance autoritario.

Profundizando aún más en el caso Venezuela, se pueden establecer las fases del proceso de apropiación del poder judicial por parte del poder ejecutivo de acuerdo a Louza Scognamiglio ${ }^{77}$, cuyas etapas principales van desde 1999 al 2016:

1) Purga judicial ejecutada en el período 1999-2003, mediante la instauración de una comisión de emergencia judicial que destituyó a jueces que habían sido nombrados en los años anteriores al período del presidente Hugo Chávez.

2) La promulgación de la Ley Orgánica del Tribunal Supremo de Justicia de 2004, que aumentó sobremanera los jueces del Tribunal Supremo de Justicia, para garantizar que los nuevos nombramientos fuesen afines al sector oficialista, lo cual fue aplicado en el período 2004-2008, tal como se indicó anteriormente.

3) La politización del Tribunal Supremo de Justicia en el período 2009-2012, lapso en el cual se promulga la Ley del Sistema de Justicia de 2009, que crea a su vez una Comisión Nacional del Sistema de Justicia para sustituir al Tribunal Supremo de Justicia en sus políticas de gobierno, administración y dirección del poder judicial. En su conformación, esta comisión tiene participación importante del poder ejecutivo y del poder legislativo, con mayoría oficialista.

4) La partidización definitiva del Tribunal Supremo de Justicia en el período 2013-2016, mediante dos hechos fundamentales: a) la adhesión del Tribunal Supremo de Justicia al Plan de la Patria ${ }^{78}$, impuesto por el poder ejecutivo y en el

\footnotetext{
76 Para mayor abundamiento al respecto, consultar: Ayala Corao (2014) y Nota de prensa de la OEA publicada en fecha 10 de septiembre de 2013, disponible en el siguiente enlace: http://www.oas.org/es/ cidh/prensa/comunicados/2013/064.asp.

77 Louza Scognamiglio (2017), pp. 101-122.

78 Para ahondar más al respecto, consultar: Asamblea Nacional de la República Bolivariana de Venezuela. Ley del Plan de la Patria: Segundo Plan Socialista de Desarrollo Económico y Social de la Nación 2013-2019 (sancionada en diciembre de 2013).
} 
que establece la ideología socialista bolivariana como eje de las políticas gubernamentales, y b) el nombramiento de otros doce jueces principales y cuatro suplentes del Tribunal Supremo de Justicia, que formaban parte del partido oficialista.

Ahora bien, Sarmiento Erazo ${ }^{79}$, además de los autores mencionados antes, sobre el caso venezolano y sobre otros países latinoamericanos indica los siguientes elementos:

- La convocatoria a la Asamblea Nacional Constituyente y reformas o modificaciones constitucionales que establecen normas fundamentales más apropiadas a la ideología del jefe de Estado y con fuerte presidencialismo; es lo que él denomina un neoconstitucionalismo que genera límites a los derechos fundamentales, porque amplía de sobremanera las atribuciones del poder ejecutivo, eliminando, al menos transitoriamente, las instituciones representativas que pueden cuestionar estos regímenes al inicio de sus mandatos.

- El protagonismo del poder judicial para favorecer al poder ejecutivo en decisiones cruciales para el mantenimiento en el poder, además de Venezuela, en Bolivia y Nicaragua, como la reelección indefinida ${ }^{80}$. Aspecto que se evidencia en estos países, Bolivia y Nicaragua, pero que hay que precisar en futuros trabajos si se acompañan de otros elementos autoritarios, como se ha especificado en Venezuela.

- La implantación del populismo, consistente en la concentración en el caudillo de la agenda y las demandas sociales a satisfacer, por sí mismo y su partido y, asimismo, la decisión de quién o cuál parte de la oposición es considerada como legítima y cuál es el enemigo a vencer, puesto que considera enemigo a gran parte del pueblo que debería representar.

- La reelección indefinida, que ya se ha mencionado antes.

2. El régimen político venezolano y sus efectos sobre la teoría política (democrática) y los derechos constitucionales, fundamentales o humanos:

79 Sarmiento Erazo (2013) y al mismo tiempo se aclara que este autor analiza Venezuela, Bolivia y Ecuador, no Nicaragua.

80 Sobre la aprobación de la reelección indefinida en Nicaragua y Bolivia, consultar con respecto a Nicaragua: Martínez Barahona y Brenes (2012) y la noticia: "Fallo judicial abre el camino a la reelección de Daniel Ortega", publicado en el Diario El Comercio de Perú. Sitio web: www.elcomercio.pe. Disponible en el enlace: http://elcomercio.pe/mundo/europa/fallo-judicial-abre-camino-reeleccion-daniel-ortega-nicaraguanoticia-357546, consultado el 12 de febrero de 2017. Y con respecto a Bolivia: el fallo del 29 de noviembre de 2017 mediante el cual el Tribunal Constitucional Plurinacional autorizó al jefe de Estado, Evo Morales, a postularse indefinidamente como candidato a la presidencia de la República, ignorando el resultado de la consulta refrendaria realizada previamente, en febrero de 2016. Para mayor abundamiento al respecto consultar el siguiente enlace: http://www.bbc.com/mundo/noticias-america-latina-42159445). 
Este acápite se dividirá en dos partes, la primera relativa a las implicaciones sobre la teoría política del régimen político venezolano y la segunda sobre sus consecuencias en los derechos constitucionales.

\subsection{El régimen politico venezolano frente a la teoría política que lo caracteriza}

Como se aprecia a pesar de las concepción democrática consagrada constitucionalmente en el régimen del Estado analizado, Venezuela, ha resurgido el autoritarismo, intuyéndose también en Bolivia y Nicaragua por la instauración de la reelección indefinida e incluso el autoritarismo en otras latitudes ${ }^{81}$.

La afirmación se demuestra contrastando los elementos arrojados en los análisis de la situación sociopolítica de Venezuela, que concuerdan con las concepciones autoritarias referidas en el punto I, donde destacan Linz, Morlino, O’Donnell, entre otros, y se alejan de las concepciones democráticas referidas en el punto II, donde resaltan las propuestas teóricas de más consenso en la doctrina académica y en las legislaciones correspondientes: Dahl, Bobbio, Ferrajoli, Nino, entre otros.

La coincidencia entre el régimen político de Venezuela y el autoritarismo planteado en el punto I del trabajo ${ }^{82}$, y los análisis de autoritarismo y populismo que incluye la democracia delegativa de O'Donnell ${ }^{83}$, se evidencia en los siguientes elementos:

1) El pluralismo es limitado o prácticamente inexistente; la oposición tiene derechos mínimos, con casi o ninguna posibilidad de obtener el poder democráticamente ${ }^{84}$.

2) La sociedad civil no es autónoma, es arrasada por el jefe del Estado, que trata de manera directa con la población y esta es cuestionada por el Estado y hasta anulada, tal como se evidenció en su eliminación, por el partido oficialis-

\footnotetext{
$81 \mathrm{Al}$ respecto se sugiere la consulta de Werner Muller (2016), quien señala la preocupación por los autoritarismos de Polonia, Hungría y Turquía.

82 Ir a puntos 1 y 1.1. de este trabajo, sobre los autoritarismos.

83 Ir al punto I.4 de este trabajo, sobre los autoritarismos y populismos.

84 Elemento importante que demuestra esta imposibilidad aparece en la figura de las inhabilitaciones políticas sobre la casi totalidad de los líderes importantes de la oposición venezolana sin debido proceso [cf. CHACín (2016), pp. 54-55].
} 
ta, en el comité de postulaciones judiciales para elegir a los jueces del Tribunal Supremo de Justicia ${ }^{85}$.

3) Existe un partido privilegiado, que es el partido oficialista, que goza de gran ventajismo en las elecciones presidenciales y en la distribución de subsidios y recursos a la población, dejando prácticamente sin participación a los partidos opositores, tal como se indicó ${ }^{86}$.

4) La implantación de la ideología propia de los autoritarismos y populismos; en este caso, la ideología socialista mediante la implantación del Plan de la Patria $2013^{87}$.

5) El exceso de personalismo, caudillismo, tal como se indicó según Sarmiento Erazo, del presidente de la República, que anula a los otros poderes como el poder legislativo $^{88}$ y el poder judicial, que es colonizado y está completamente a sus órdenes ${ }^{89}$.

6) El derecho es minimizado, solo conveniente cuando la interpretación y aplicación de la Constitución favorece al poder ejecutivo ${ }^{90}$; de allí lo importante del afán del presidente y su partido de someter al poder judicial.

En efecto, en el gobierno de Venezuela el papel del jefe de Estado es casi absoluto, elegido de manera indefinida para decidir cualquier cosa, ignorando o penetrando los otros poderes y anulando a la oposición, imposibilitando que esta pueda tener una real posibilidad de convertirse en gobierno, tal como debe ocurrir en los regímenes democráticos, aprovechándose el gobierno además de un partido oficial, casi único, por ser el que realmente tiene posibilidad de detentar el poder.

85 Tal como se señaló en las notas al pie 73 y 74.

86 García (2012), Benítez y González (2016), Sarmiento (2013) y Louza (2017).

87 Cf. Plan de la Patria: Ley del Plan de la Patria: Segundo Plan Socialista de Desarrollo Económico y Social de la Nación 2013-2019.

$88 \mathrm{El}$ cual es controlado y presionado para el nombramiento de los magistrados del Tribunal Supremo de Justicia [cf. Benítez y GonZÁlez (2016)].

89 Cf. Louza (2017) y su explicación de las fases de colonización del poder judicial en Venezuela en el punto anterior de este trabajo.

90 Tal como ocurrió con la reelección indefinida que, a pesar de haber sido rechazada en un referendo aprobatorio, fue propuesta de nuevo, lo cual violentaba el principio de soberanía y democracia de la Constitución venezolana. A pesar de esto, la Sala Constitucional del Tribunal Supremo de Justicia desestimó los recursos de inconstitucionalidad contra esta nueva propuesta (indicado en la nota al pie No 73 de este trabajo). 
El porqué de este resurgir autoritario a pesar de los obstáculos democráticos, muchos de ellos presentes en la normativa interna e internacional de este país ${ }^{91}$, se debe a lo siguiente.

La colonización del poder judicial por parte del poder ejecutivo a través de los mecanismos de mayoría parlamentaria de los cuales gozan en virtud de que es un gobierno que llega al poder con un gran apoyo popular, lo que se traduce en el control de los parlamentos o asambleas nacionales, que le permite designar los miembros del poder judicial, por ser estos parlamentos decisivos en el nombramiento de los integrantes de los principales tribunales constitucionales o cortes supremas encargados de garantizar la permanencia de la democracia y el Estado de derecho.

Esto ha generado la figura de la reelección indefinida, que viola la alternabilidad, principio democrático esencial, que precisamente garantiza que la democracia se oponga a las dictaduras o autoritarismos, regímenes que usan el ejercicio indeterminado en el poder para suprimirla. Es decir, la reelección indefinida constituye la patente de corso que le adjudica al jefe de Estado la posibilidad real de permanecer prolongadamente de manera indeterminada en el poder y por ende la patética posibilidad de pasar de una democracia a una forma de gobierno autoritaria.

Otro efecto importante de la colonización del poder judicial en Venezuela consiste en el reconocimiento por parte de este de la constitucionalidad de leyes, decretos y demás normas jurídicas y políticas y acciones gubernamentales arbitrarias que ponen en jaque los derechos civiles y políticos, como restricciones de la libertad de prensa, proscripción de partidos políticos o sus principales líderes ${ }^{92}$, arbitrariedades todas que favorecen al jefe de Estado y su partido.

El resultado es un poder judicial no cónsono con las exigencias de la democracia constitucional, planteadas por Nino y Ferrajoli ${ }^{93}$, consistentes en la presencia de un sistema judicial que garantice la efectividad de los derechos fundamentales propios de un régimen democrático.

\footnotetext{
91 Tal como se establece en la Constitución vigente venezolana y en tratados internacionales ratificados por esta, ya que si bien la Convención Americana fue denunciada, tratado eje del sistema interamericano, aún quedan otros tratados ratificados por Venezuela que siguen vigentes: el Pacto Internacional de Derechos Civiles y Políticos, la Carta Democrática Interamericana, la Declaración Americana de los Derechos y Deberes del Hombre, la Declaración Universal de los Derechos Humanos, entre otros.

92 Tal como ocurre en Venezuela con la figura de las inhabilitaciones políticas sin control judicial [cf. Chacín (2016), pp. 54-55].

93 Destacadas en el punto II.2 de este trabajo.
} 


\subsection{Las consecuencias del caso venezolano sobre los derechos constitucionales, fundamentales o humanos}

En el señalado contexto autoritario del caso venezolano, es oportuno destacar las lesiones a los valores, principios y derechos constitucionales, fundamentales o humanos:

1) El principio de la división e independencia de los poderes que garantiza el Estado de derecho es arrasado.

2) Lesión de los derechos políticos de la oposición, como el sufragio pasivo ${ }^{94}$.

3) Eliminación de elecciones democráticas (lesión al derecho al sufragio), es decir, lesión del principio de soberanía que recae en el pueblo o el principio democrático propiamente dicho, al ser las elecciones parcializadas, con ventajismo presidencial y con un órgano electoral, al igual que el poder judicial, penetrado por el oficialismo.

4) Lesiones de derechos civiles y políticos a líderes y partidos opositores, como debido proceso, libertad de expresión, libertad de información, acceso a los medios de comunicación en campañas electorales, etc.

5) La consecuencia de la implantación de la reelección indefinida que pone en jaque la permanencia del régimen político democrático con todos sus derechos y garantías para el ciudadano.

6) El retroceso brutal en materia de derechos humanos, al denunciar y dejar de tener vigor en Venezuela la Convención Americana ${ }^{95}$ o Pacto de San José; de esta manera, la Corte Interamericana de los Derechos Humanos ya no tiene jurisdicción en este país.

7) Todo lo cual se ha generado por el control del poder judicial, que le da un barniz de constitucionalidad a todas las acciones arbitrarias e inconstitucionales señaladas.

\section{Conclusiones}

Las conclusiones que se muestran fueron adelantadas en el punto anterior, es por eso qué esta parte apuntará a unas recomendaciones y reflexiones producto de la realidad analizada en este caso en Venezuela y su quebrantamiento de la

94 Evidente en la figura de las inhabilitaciones políticas masivas citadas anteriormente.

95 Véase el punto anterior, referido al neoautoritarismo en Venezuela, y la nota al pie № 75. 
democracia, y las eventuales implicaciones en otros países como Bolivia y Nicaragua, a los cuales también se hizo referencia:

- Se reconoce el avance de la democracia como teoría que ha permeado favorablemente los ordenamientos y en consecuencia los regímenes políticos de la mayoría de los países del mundo occidental, hasta en Venezuela, aunque en este país solo en el aspecto formal.

- No obstante, existe una grieta, factor principal, que genera que el régimen democrático no se haya hecho efectivo en Venezuela: la adhesión o penetración del poder judicial por parte del jefe de Estado y su partido.

- Problema que aparentemente no es solo de Venezuela, sino también de Bolivia y Nicaragua, países en los cuales se ha establecido también la reelección indefinida con sus eventuales efectos nefastos para la continuidad democrática. Por esta razón se considera pertinente el estudio sobre el sistema político de estos países, si están o no avanzando hacia un régimen autoritario como el venezolano, lo cual pudiera significar una muestra importante del descenso democrático en el ámbito latinoamericano.

- El reto para la teoría democrática, reconocida por los ordenamientos jurídicos de todos los países del ámbito latinoamericano, salvo Cuba, es que esta forma de gobierno sea efectiva, es decir, una realidad fáctica, en el sentido de que impidan verdaderamente prácticas autoritarias que restrinjan severamente los derechos democráticos.

- ¿Cómo lograr esto?, ¿cómo impedir que los derechos fundamentales y la práctica democrática se desvirtúen? Este escrito no tiene la solución, ni es su pretensión tenerla, pero la salida debe propender a remover de la realidad, entre otros factores, el aquí señalado, la conquista, como en Venezuela, del poder judicial por el jefe de Estado y su partido. Ya esto será una tarea de profundizar la legislación pertinente, la política respectiva que haga efectiva esa legislación democrática, lo cual constituye un reto para los Estados y la propia comunidad internacional, donde el elemento de cultura política -o, mejor dicho, cultura democrática- sea un estándar de valores políticos que constituyan una moral política de principios inquebrantables por cualquier gobierno animado a perpetuarse en el poder y a acabar con las conquistas jurídicas civiles y políticas.

\section{BibLIOGRAFÍA CITADA}

ARTíCULOS DE REVISTAS CIENTÍFICAS, ENTREVISTAS Y LIBROS

ARENDT, Hannah (1998): Los orígenes del totalitarismo. (Madrid, Taurus). 624 p. 
Ayala Corao, Carlos (2012): "Inconstitucionalidad de la denuncia de la Convención Americana sobre Derechos Humanos en Venezuela", en Estudios Constitucionales (Año 10, No 2), pp. 643-682.

Benítez, Vicente, y GonZÁlez, German (2016): "El rol de las cortes y la protección de la democracia: una aproximación desde regímenes transicionales", en Revista de Derecho del Estado (No 36), pp. 41-67.

BRuM, Pablo (2011): "El impacto del totalitarismo en el siglo XX”, en Universidad ORT. Facultad de Administración y Ciencias Sociales. Montevideo. Uruguay, (No 62) febrero, pp. 1-48, [fecha de consulta: 29 de abril de 2018]. [Disponible en: https://dspace.ort.edu.uy/bitstream/handle/20.500.11968/2776/ documentodeinvestigacion62.pdf].

Bobbio, Norberto (1986): El futuro de la democracia (D.F. México, Fondo de Cultura Económica).

Bovero, Michelangelo (2006): "El liberal-socialismo para Bobbio y para nosotros", en Doxa-Cuadernos de Filosofía del Derecho (No 29), pp. 123-130.

BurT, Jo-Marie (2011): Violencia y autoritarismo en el Perú: Bajo la sombra de Sendero y la dictadura de Fujimori (Lima, Instituto de Estudios Peruanos).

CASAL, Jesús María (2009): "Algunos cometidos de la jurisdicción constitucional en una democracia", en Compendio: Jurisdicción constitucional, democracia y Estado de derecho, pp. 109-145.

Cazor, Kamel (2007): "Constitucionalismo y umbral democrático en Chile: Hacia una nueva teoría constitucional", en Revista Ius et Praxis (Año 13, No 1), pp. 45-74.

Couso, Javier. (2004): “Consolidación de la democracia y poder judicial: Los riesgos de la judicialización de la política”, en Revista de Ciencia Política (Vol. XXIV No 2), pp. 29-48.

Chacín, Ronald (2016): "Consideraciones sobre la democracia judicial: El caso venezolano”, en Revista Frónesis (Volumen 23 No 1), pp. 46-63.

Dahl, Robert (1962): Who Governs?: Democracy and Power in an American City (New Have, Yale University Press).

DAHL, Robert (1992): La democracia y sus críticos (Barcelona, Paidós).

Dworkin, R. (1984): Los derechos en serio (Traducc. Marta Guastavino, Barcelona, Ariel).

Ferrajoli, Luigi. (2008): Democracia y garantismo (Madrid, Trotta).

García de Enterría, Eduardo (2001): La Constitución como norma y el Tribunal Constitucional, Tercera Edición (Madrid, Civitas). 
García OÑoro, Jairo (2012): "Latinoamérica: Entre la democracia y el autoritarismo", en Estudios Políticos (No 41), pp. 15-35.

Gorczevski, Clover, y Muller, Caroline (2010): "El resurgimiento de un concepto: la búsqueda del verdadero sentido a la democracia en la sociedad contemporánea”, en Estudios Constitucionales (Año 8, No 2), pp. 15-30.

Hassemer, W. (2009): "Jurisdicción constitucional en una democracia", en Compendio: Jurisdicción constitucional, democracia y Estado de derecho, pp. 17-56.

LiNZ, Juan J. (1978): “Una interpretación de los regímenes autoritarios”, en Revista de Sociología (No 8), pp. 11-26.

Louza Scognamiglio, Laura (2017). "La estrecha y necesaria relación entre independencia judicial, Estado de derecho, el respeto de los derechos humanos y democracia: Venezuela como caso de estudio", en: Acta Sociológica (No 72), pp. 95-127.

Martínez Barahona, Elena, y Brenes, Amelia (2012): "Y volver, volver: Un análisis de los casos de intervención de las cortes supremas en la reelección presidencial en Centroamérica”, en Anuario de Estudios Centroamericanos (No 38), pp. 109-136.

MiLL, Johan Stuart (2007): Sobre la libertad (Madrid, Biblioteca Edaf).

Morlino, Leonardo (2004): "Las alternativas no democráticas", en Postdata (No 10), pp. 149-183.

MulLER, Jan-Werner (2016): "El problema de la democracia no liberal”, en Diario La Nación, San José de Costa Rica, publicado el 29.01.2016 [fecha de consulta: 2 de abril de 2018]. [Disponible en: http://www.nacion.com/opinion/ foros/problema-democracia-liberal_0_1539446044.html].

Nino, Carlos Santiago (2003): La constitución de la democracia deliberativa (Barcelona, Gedisa).

O’Donnell, Guillermo (1994): Democracia delegativa. Universidad de Buenos Aires. Facultad de Ciencias Sociales y Política, sitio web: liderazgos-sXXi. com.ar [fecha de consulta: 4 de abril de 2018]. [Disponible en: http://www. liderazgos-sxxi.com.ar/bibliografia/Democracia-delegativa_.pdf], publicado originalmente como "Delegative Democracy", Journal of Democracy, Vol. 5, January 1994: 55-69. National Endowment for Democracy and The Johns Hopkins University Press.

Rodríguez Rojas, Pedro (2010): "Venezuela: del neoliberalismo al socialismo del siglo XXI”, en Política y Cultura (No 34), pp. 187-211.

Rousseau, J. (1998): El contrato social (Buenos Aires, Editorial Losada). 
Santana Castillo, Joaquín (2008): "Neoliberalismo, gobernabilidad y nuevos movimientos sociales. El cambio político en diferentes naciones de Latinoamérica”, en CLIO-América (volumen 2 No 4), pp. 213-237.

Sarmiento Erazo, Juan Pablo (2013): "Populismo constitucional y reelecciones, vicisitudes constitucionales en la experiencia democrática”, en Estudios Constitucionales, (Año 11, No 1), pp. 213-237. Centro de Estudios Constitucionales de la Universidad de Talca. Talca, Chile, [fecha de consulta: 12 de marzo de 2018]. [Disponible en: https://scielo.conicyt.cl/pdf/estconst/ v11n1/art16.pdf].

SARTORI, Giovanni (1988): Teoría de la democracia (Barcelona, Alianza).

Tocqueville, A. (2010): La democracia en América (Madrid, Editorial Trotta).

Uharte, Luis Miguel (2008): "Venezuela: Del ajuste neoliberal a la promesa del socialismo del siglo XXI”, en HAOL (No 16), pp. 127-147.

Vallespín, Fernando (2017): ¿Por qué el populismo?, en Círculo Cívico de Opinión (Cuaderno No 19), pp. 7-19.

VARGAS, Juan Carlos (2011): "Los orígenes del totalitarismo de Hannah Arendt y la manipulación de la legalidad (el desafío totalitario de la Ley)", en Revista Boliviana de Derecho (No 11), pp. 114-131.

VÁsquez, R. (2001): Liberalismo, Estado de derecho y minorías (México D.F., Paidós).

Zovatto, Daniel (2018): "El estado de las democracias en América Latina a casi cuatro décadas del inicio de la tercera ola democrática", en Revista Derecho Electoral (No 25), [fecha de consulta: 10 de abril de 2018]. [Disponible en: http://www.tse.go.cr/revista/art/21/aguilar_olivares.pdf].

\section{DOCUMENTOS ELECTRÓNICOS}

Instituto Mexicano para la competitividad (IMCO): Índice de Democracia 2016 vía The Economist, [fecha de consulta: 30 de abril de 2018]. [Disponible en: https://imco.org.mx/politica_buen_gobierno/indice-de-democracia-2016-viathe-economist/].

The Economist. Democracy Index 2017: Free speech under attack, [fecha de consulta: 3 de abril de 2018]. [Disponible en: http://pages.eiu.com/rs/753RIQ-438/images/Democracy_Index_2017.pdf?mkt_tok=eyJpIjoiWkRKbU1HWmxNVEUwTW1FdyIsInQiOiJPdlltVFV0blFRQzZNVERCZHhV eitZRElmUGplOHh3NWs1d2wzVzdRS1JvNU1kVmUxQVRESU9LbE- 
VSOVwvR1F4aG1PV1NIS0ZZcng4NzBcLzVNZ09JOUxiZU5TTEVPekVHayttOTRqQkQ5TkNzWGNtRlowQTZ0UzlUK0pDdm9PVGlcLyJ9].

\section{NORMAS JURÍDICAS CITADAS}

Asamblea Constituyente-Congreso de la República de Bolivia. Constitución Política del Estado. Aprobada en el referendo constituyente de enero de 2009 (versión oficial), [fecha de consulta: 2 de marzo de 2018]. [Disponible en: https://www.oas.org/dil/esp/Constitucion_Bolivia.pdf].

Asamblea Nacional. Texto de la Constitución Política de la República de Nicaragua de 2003, con la reforma de 2014 y demás reformas incorporadas. Gaceta Oficial No 32, AÑO CXVIII, [fecha de consulta: 30 de marzo de 2018].

Asamblea Nacional de la República Bolivariana de Venezuela. Ley del Sistema de Justicia. Gaceta oficial No 39.276, de 1 de octubre de 2009, [fecha de consulta: 3 de mayo de 2018]. [Disponible en: file://C:/Users/Ronald1/Documents/ LeydelSistemadeJusticia.pdf].

Asamblea Nacional de la República Bolivariana de Venezuela. Ley Orgánica del Tribunal Supremo de Justicia. Gaceta oficial No 37.942, de 20 de mayo de 2004, [fecha de consulta: 3 de abril de 2018]. [Disponible en: http://www. oas.org/juridico/spanish/mesicic2_ven_anexo_44_sp.pdf].

Asamblea Nacional de la República Bolivariana de Venezuela. Ley del Plan de la Patria: Segundo Plan Socialista de Desarrollo Económico y Social de la Nación 2013-2019. Gaceta oficial No 6.118, extraordinario de 4 de diciembre de 2013, [fecha de consulta: 4 de junio de 2018]. [Disponible en: http://gobiernoenlinea.gob.ve/home/archivos/PLAN-DE-LA-PATRIA-2013-2019.pdf] .

Asamblea Nacional Constituyente. Constitución de la República Bolivariana de Venezuela. 1999. Gaceta Oficial de la República de Venezuela No 36.860, Ordinario, 30.12.1999. Reimpresa por error material del ente emisor. Caracas, Venezuela. Gaceta Oficial de la República Bolivariana de Venezuela No 5.453, extraordinario, 24.03.2000. Enmienda No 1 de la Constitución de la República Bolivariana de Venezuela. Gaceta Oficial de la República Bolivariana de Venezuela No 5.908, extraordinario, 19.02.2009.

Conferencia Especializada Interamericana sobre Derechos Humanos. Convención Americana sobre Derechos Humanos. Suscrita en San José de Costa Rica el 22 de noviembre de 1969, [fecha de consulta: 20 de marzo de 2018]. [Disponible en: https://www.oas.org/dil/esp/tratados_b-32_convencion_americana_sobre_derechos_humanos.htm]. 


\section{JURISPRUDENCIA CITADA}

Tribunal Supremo de Justicia de Venezuela. Sala Constitucional. Sentencia de fecha 29.4.2008, ponente: Luisa Estella Morales, Expediente No 2008-0341, caso: Luis Hueck Henriquez.

Fundación Verdad Venezuela (2009): Tribunal Supremo de Justicia de Venezuela. Sala Constitucional. Sentencia de fecha 3.2.2009, ponente: Francisco Carrasquero, Exp. No 08-1617.

Óscar Arnal (2009): Tribunal Supremo de Justicia de Venezuela. Sala Constitucional. Sentencia de fecha 3.2.2009, ponente: Francisco Carrasquero. Exp. No 08-1611.

Fundación Orión, Derechos Civiles y Militares (2009): Tribunal Supremo de Justicia de Venezuela. Sala Constitucional. Sentencia de fecha 14.7.2009, ponente: Arcadio Delgado. Exp. No 09-0165.

\section{PRENSA}

BBC Mundo Redacción: "El Tribunal Constitucional de Bolivia autoriza a Evo Morales a buscar la reelección como presidente sin límites”. Publicado el 29 de noviembre de 2017, [fecha de consulta: 3 de abril de 2018]. [Disponible en: http://www.bbc.com/mundo/noticias-america-latina-42159445].

Comunicación Continua. Venezuela: "Organizaciones sociales de derechos humanos exigen suspender la designación de magistrados y magistradas del Tribunal Supremo de Justicia”. Publicado vía digital el 10 de diciembre de 2015, [fecha de consulta: 3 de mayo de 2018]. [Disponible en: http://comunicacioncontinua.com/54357-2/].

Diario El Comercio. "Fallo judicial abre camino a reelección de Daniel Ortega en Nicaragua”. Publicado el 20.10.2009. Sitio web: elcomercio.pe, [fecha de consulta: 3 de abril de 2018]. [Disponible en: http://elcomercio.pe/mundo/ europa/fallo-judicial-abre-camino-reeleccion-daniel-ortega-nicaragua-noticia-357546].

Diario La Nación. "Daniel Ortega va a elecciones en Nicaragua sin oposición ni observadores". Publicado el 3 de agosto de 2016. Managua-Nicaragua, [fecha de consulta: 4 de abril de 2018]. [Disponible en: https://www.nacion.com/ el-mundo/politica/daniel-ortega-va-a-elecciones-en-nicaragua-sin-oposicionni-observadores/4BZT4X7CZ5EFBPXFEDQ2YFQHIE/story/]. 
Efemérides Venezolanas. "Venezolanos dijeron no a la reforma”, por Eugenio Martínez. Publicado en el diario El Universal el 3 de diciembre de 2007, [fecha de consulta: 3 de abril de 2018]. [Disponible en: http://www.efemeridesvenezolanas.com/sec/his/id/119/?show=1].

Organización de Estados Americanos (OEA). Nota de Prensa de la OEA publicada en fecha 10 de septiembre de 2013, [fecha de consulta: 3 de abril de 2018]. [Disponible en: http://www.oas.org/es/cidh/prensa/comunicados/2013/064. asp]. 